\title{
PRELIMINARY NOTES ON ZOEA AND MEGALOPA OF THE GIANT SPIDER CRAB, MACROCHEIRA KAEMPFERI DE HAAN
}

AUTHOR(S):

Tanase, Hidetomo

CITATION:

Tanase, Hidetomo. PRELIMINARY NOTES ON ZOEA AND MEGALOPA OF THE GIANT SPIDER CRAB, MACROCHEIRA KAEMPFERI DE HAAN. PUBLICATIONS OF THE SETO MARINE BIOLOGICAL LABORATORY 1967, 15(4): 303-309

ISSUE DATE:

1967-12-20

URL:

http://hdl.handle.net/2433/175473

RIGHT: 


\title{
PRELIMINARY NOTES ON ZOEA AND MEGALOPA OF THE GIANT SPIDER CRAB, MACROCHEIRA KAEMPFERI DE HAAN ${ }^{13}$
}

\author{
Hidetomo TANASE \\ Seto Marine Biological Laboratory
}

With 3 Text-figures

The giant spider crab, Macrocheira kaempferi, is the biggest member of all recent Arthropoda and inhabits only the deep waters, ranging 50 to $200 \mathrm{~m}$, off the Pacific coast of Japan.

In early spring, a noticeable number of mature individuals come up to shallower place of the southeastern coast of the Kii Channel near our laboratory and are often caught by trawl or trammel nets. Very probably these giant spider crabs belong to the spawning migratory population, because many of captured carbs display copulation in the aquarium and most of females collected in the early season are holding eggs. So far as I am aware, the life history of this crab is yet quite unknown except for AIkAWA's paper (1941) which presents the description and figures of its first stage zoca.

Fortunately I had some chances to observe the hatching out of larvae of this $\mathrm{crab}$ in the laboratory aquarium in these years. Then, I tried to rear those larvae under artificial conditions to contribute somewhat to the study of the life history of this huge crab. In the spring of 1966, about twenty newly hatched zoeae were reared and a single individual of them succeeded to attain the megalopa through two zoean stages. Again in this spring, three individuals of about 140 larvae were grown to the megalopa. Here in this paper, the characteristic features of these larvae are given together with some figures.

I wish to express my hearty thanks to Messrs. Ch. Araga and S. Nishimura of the Seto Marine Biological Laboratory for their valuable advices to this work and also to Prof. H. Utinomi and Dr. T. Tokioka of the Laboratory for their kindness in reading the manuscript.

\section{Material and Methods}

Several ovigerous females were obtained by trawl-net fishery off Minabe, about 5 kilometers north of the Laboratory. These females were kept and observed in a

1) Contributions from the Seto Marine Biological Laboratory, No. 476.

Publ. Seto Mar. Biol. Lab., XV (4), 303-309, 1967.

(Article 18) 
tank of the Laboratory aquarium, 11.8 tons in volume. The first zoeal larvae hatched out there on the 11th of March 1967. Newly hatched zoeae were reared in 7 small glass vessels, $24 \mathrm{~cm}$ in diameter and in water of $8 \mathrm{~cm}$ deep. Each vessel received 20 individuals. Zoeae always swam around in the vessel and showed a strong positive phototaxis. Water temperature was maintained in the range of $14.0^{\circ}$ to $19.0^{\circ} \mathrm{C}$ during the rearing period. The zoeae were fed on the early nauplii of the brine shrimp, and lived as long as 26 days at the maximum, some attaining the megalopa stage.

Measurements of body parts were made in the ways mentioned below: carapace length is the distance from the front margin of the eye to the hindmost margin of carapace; length of rostral spine is that from the front margin of the eye to the tip of spine; length of dorsal spine is that from the hind margin of carapace to the tip of spine; telson length is that from the hind margin of the 4th somite to the center of the base of telson fork.

\section{Descriptions}

(1) First stage zoea (Fig. 1, A-H)

The first stage zoeae examined by myself are almost similar to those shown by Aikawa, except for several slight differences given in Table 1. Larvae of this stage moult in 9 to 12 days after hatching.

Table 1. Comparison between Aikawa's first stage zoca and that of the present material.

\begin{tabular}{llc}
\hline \multicolumn{1}{c}{ Body parts } & Aikawa's paper & this paper \\
\hline Number of hairs on 1st ant. & 4 & 3 \\
Number of hairs on exopodite of 2nd ant. & 3 & 2 \\
Number of hairs on endopodite of 1st mx. & $6-1$ & $4-1$ \\
Number of hairs on endopodite of 1st mxp. & 5 & 4 \\
Number of joints on endopodite of 2nd mxp. & 3 & 2 \\
Number of hairs on endopodite of 2nd mxp. & $6-1-1$ & $6-1$ \\
A pair of extra-hairs on telson & occur & sometimes occur \\
\hline
\end{tabular}

Table 2. Measurements on first stage zoea.

\begin{tabular}{ccccc}
\hline No. & Carapace length & Rostral spine & Dorsal spine & Telson length \\
\hline 1 & $1.20 \mathrm{~mm}$ & $0.82 \mathrm{~mm}$ & $1.64 \mathrm{~mm}$ & $0.26 \mathrm{~mm}$ \\
2 & 1.22 & 0.88 & 1.62 & 0.26 \\
2 & 1.10 & 0.84 & 1.56 & 0.28 \\
4 & 1.12 & 0.90 & 1.48 & 0.26 \\
5 & 1.24 & 0.82 & 1.52 & 0.28 \\
Average & 1.18 & 0.85 & 1.56 & 0.27 \\
\hline
\end{tabular}


Table 3. Measurements on second stage zoea.

\begin{tabular}{ccccc}
\hline \hline No. & Carapace length & Rostral spine & Dorsal spine & Telson length \\
\hline 1 & $1.58 \mathrm{~mm}$ & $1.04 \mathrm{~mm}$ & $1.68 \mathrm{~mm}$ & $0.48 \mathrm{~mm}$ \\
2 & 1.68 & 1.08 & 1.60 & 0.44 \\
3 & 1.46 & 1.06 & 1.96 & 0.42 \\
Average & 1.57 & 1.06 & 1.75 & 0.45 \\
\hline
\end{tabular}

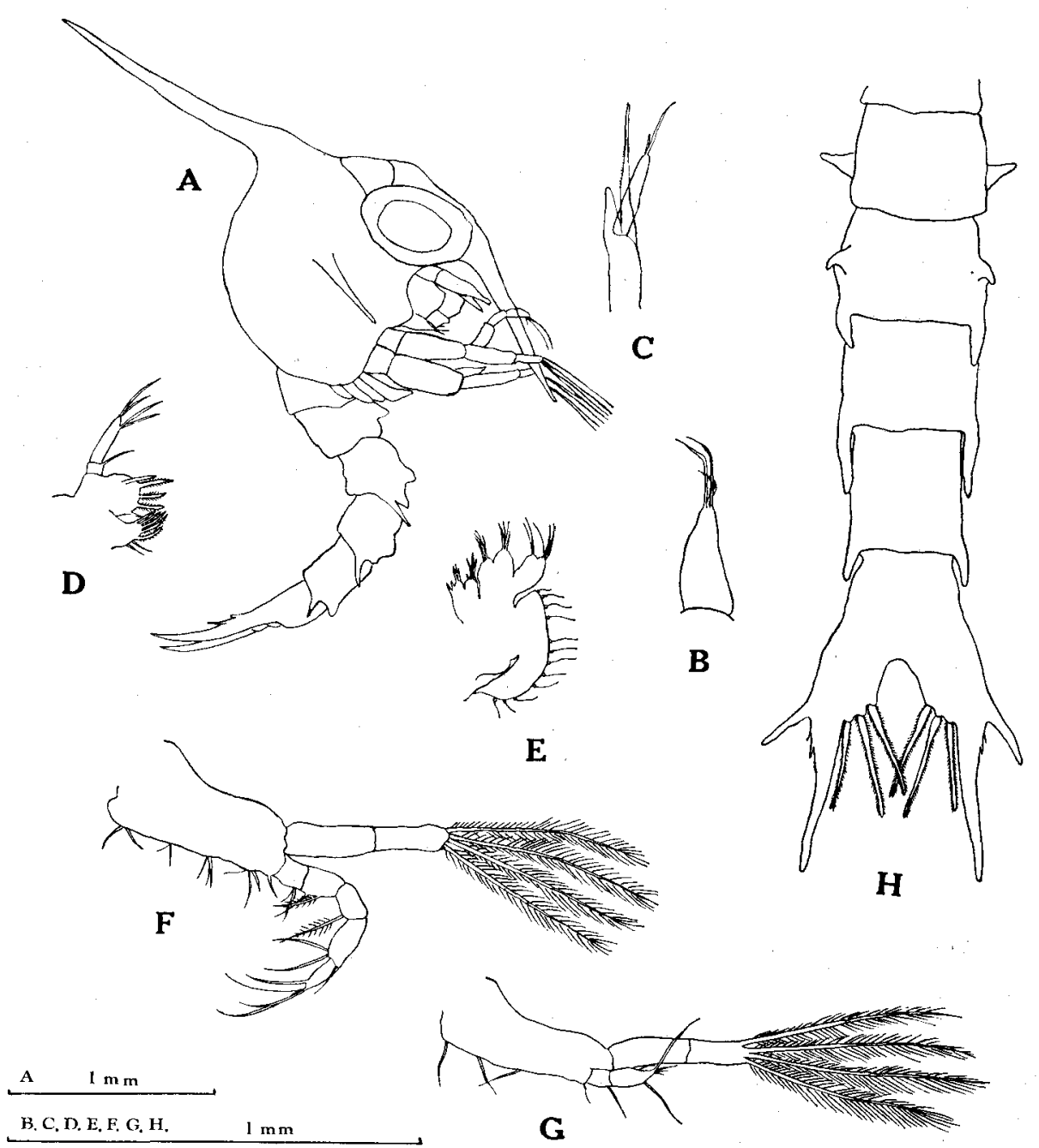

Fig. 1. Macrocheira kaempferi DE HAAN, the first stage zoca. A. Lateral view, B. 1st antenna, C. 2nd antenna, D. 1st maxilla, E. 2nd maxilla, F. 1st maxilliped, G. 2nd maxilliped, H. Abdomen (dorsal view). 
(2) Second stage zoea (Fig. 2, A-H)

The first antenna (Fig. 2, B) is one-segmented as in the first stage, but provided with a thumb-like prominence on the inner edge at the level of the distal one-fourth; it is furnished with 5 long simple setae at the tip and with 3 a little shorter ones near the middle of the range between the distal end and the thumb-like prominence. Exopodite of the second antenna (Fig. 2, C) has 3 unequal hairs on tip. Endopodite of first maxilla (Fig. 2, D) 2-jointed; its distal joint bears 6 hairs on tip and the proximal joint has a hair at the inner distal corner. Armature on other parts of the first maxilla and on the whole second maxilla (Fig. 2, E) has become a little more complicated than in the first stage zoea. Exopodite of maxillipeds (Fig. 2, F, G) 2jointed and its terminal joint has 6 hairs. ( 4 hairs in the first stage zoea) Other parts of maxillipeds do not show any significant differences between the first and second stages. The number of hairs on the posterior margin of the protopodite seems variable individually. The telson of the first stage zoea is split into the 6th abdominal segment and telson in the second stage (Fig. 2, H). The dorsal aspect of the abdominal segments 2nd to 5 th in the second stage zoea is the same as in the first stage. But on the ventral side, each postero-lateral corner of 2nd to 6 th abdominal segments is projected out as a rudimentary pleopod. Pleopods are non-segmented and devoid of any hairs. The structure of telson shows no difference between the first and second stages. The zoea of this stage will have the second moulting in 12 to 14 days after the first moulting and enter the megalopa stage. These two moults are done in 20 days at the minimum at the water temperature 14.0 to $19.0^{\circ} \mathrm{C}$.

(3) Megalopa (Fig. 3, A-I).

Table 4. Measurements on megalopa.

\begin{tabular}{cllllll}
\hline No. & $\begin{array}{c}\text { Carapace } \\
\text { length }\end{array}$ & $\begin{array}{c}\text { Carapace } \\
\text { width }\end{array}$ & $\begin{array}{c}\text { Length of } \\
\text { abdomen }\end{array}$ & $\begin{array}{c}\text { Rostral } \\
\text { spine }\end{array}$ & $\begin{array}{c}\text { Dorsal } \\
\text { spine }\end{array}$ & 2nd ant. \\
\hline 1 & $1.98 \mathrm{~mm}$ & $1.74 \mathrm{~mm}$ & $1.48 \mathrm{~mm}$ & $0.46 \mathrm{~mm}$ & $0.64 \mathrm{~mm}$ & $1.48 \mathrm{~mm}$ \\
2 & 2.22 & 1.96 & 1.52 & 0.50 & 0.74 & 1.26 \\
\hline
\end{tabular}

Carapace more or less triangular and still retains of all carapacial spines which are much reduced in size. Two small prominences appear newly in the mesogastric region, the anterior is slightly smaller than the posterior. There are swellings respectively in the mesobranchial region posteriorly and in the hepatic to epibranchial region anteriorly, thus the feature of megalopa carapace reminds us of the carapace of adults. First antenna and mouth parts including maxillipeds were not shown here, because it was hardly possible to me, not well experienced in dissecting fine structures, to take these appendages in a perfect condition off so delicate specimen of this megalopa. Second antenna (Fig. 3, B) is 8 segmental; distal joint has 3 hairs on tip. The proximal joint with a spinule at the outer distal corner, the third joint with 2 setae at the outer and a seta at the inner distal corner, and the 6 th joint with a hair 


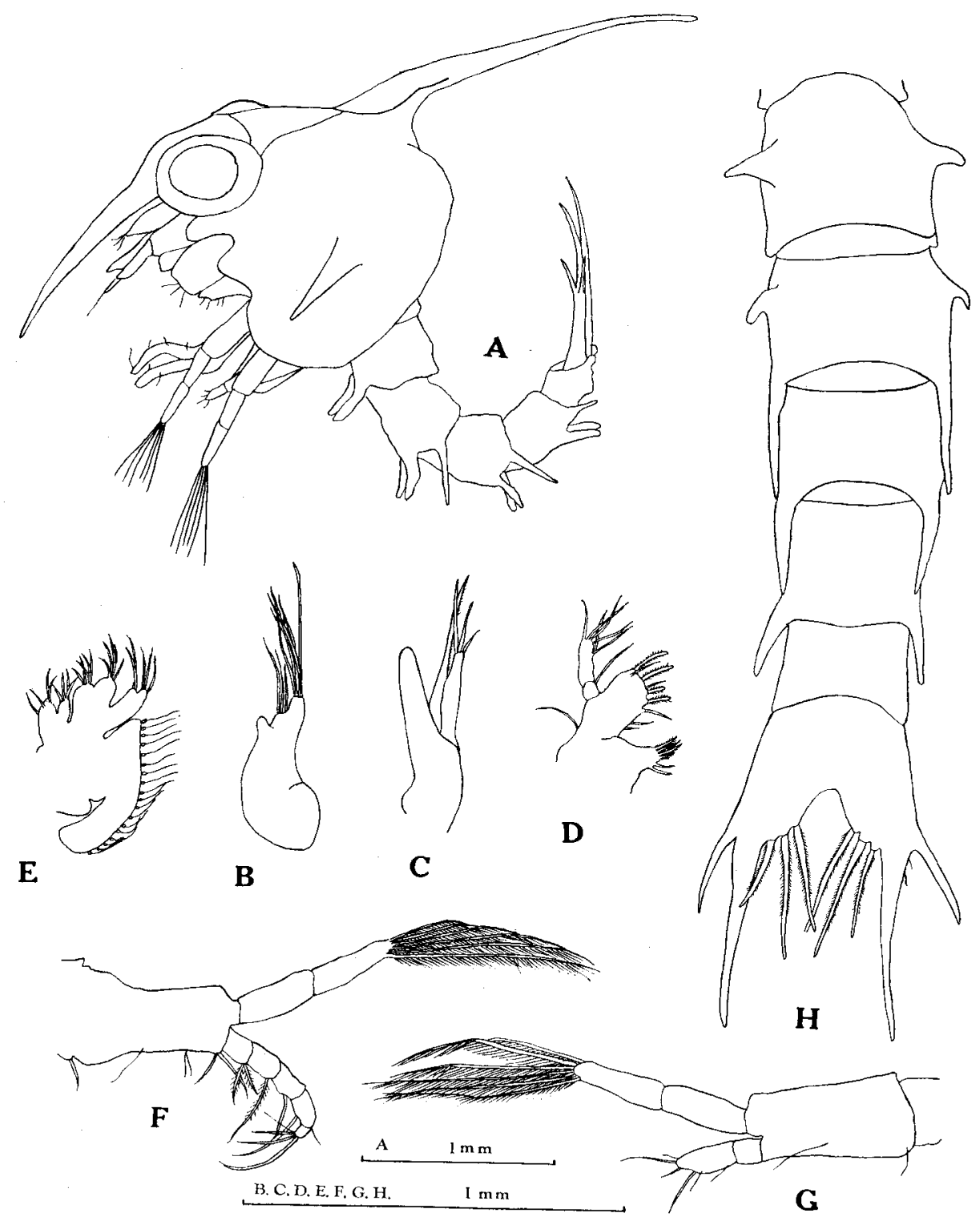

Fig. 2. Macrocheira kaempferi $\mathrm{DE}$ HAAN, the second stage zoea. A. Lateral view, B. 1st antenna, C. 2nd antenna, D. 1st maxilla, E. 2nd maxilla, F. 1st maxilliped, G. 2nd maxilliped, H. Abdomen (dorsal view).

at each of inner and outer distal corners. Cheliped (Fig. 3, G) is still short but stout. Movable finger (dactylus) is about half as long as propodus, any distinct joints are not defined in other parts of cheliped. Pereiopods are built generally as in adults, measurements of respective sements are given in table 5 . 


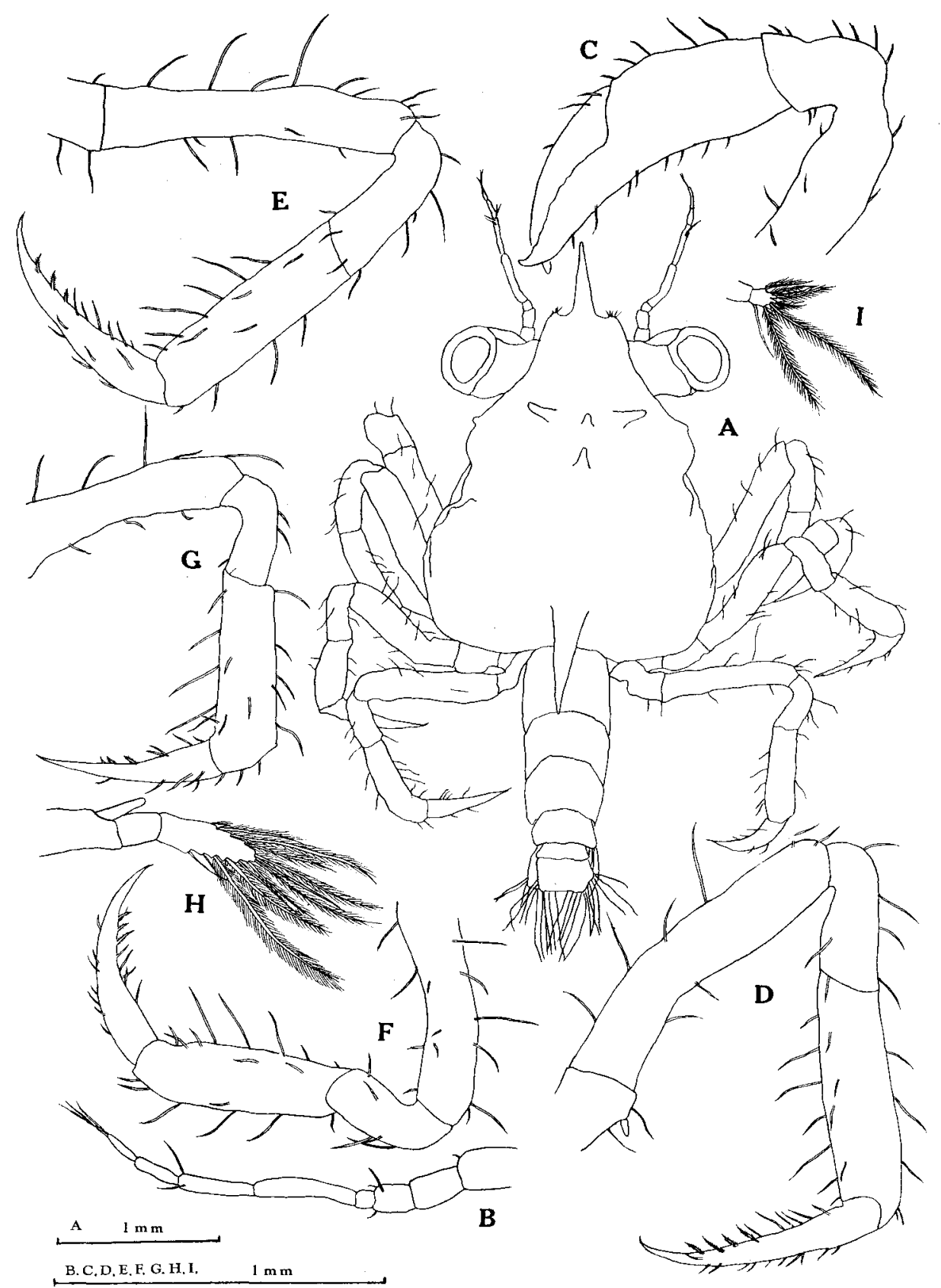

Fig. 3. Macrocheira kaempferi DE HAAN, megalopa. A. Dorsal view, B. 2nd antenna, C. Cheliped, D. 1st leg, E. 2nd leg, F. 3rd leg, G. 4th leg, H. 1st pleopod, I. Last pleopod, 
Table 5. Measurements of respective segments on legs.

\begin{tabular}{lllll} 
& Dactylus & Propodus & Carpus & Merus \\
\hline 1st leg & $0.75 \mathrm{~mm}$ & $0.64 \mathrm{~mm}$ & $0.40 \mathrm{~mm}$ & $0.93 \mathrm{~mm}$ \\
2nd leg & 0.66 & 0.65 & 0.43 & 0.91 \\
3rd leg & 0.58 & 0.58 & 0.33 & $0.64+$ \\
4th leg & 0.54 & 0.56 & 0.31 & $0.63+$ \\
\hline
\end{tabular}

Abdomen 7-segmented; ventral side of 2 nd to 6 th somites are provided each with a pair of pleopods. Lateral knobs on 2nd and 3rd somites disappear. Posterolateral projections of 3 rd to 5 th somites disappear, too. Pleopods (Fig. 3, H) are built similarly except for the last pair. In the first pleopod, exopodite is 2-segmented; the distal segment is furnished with about a dozen plumose setae around the distal half of the segment and 2 simple hairs in the outer edge at the proximal end of the series of plumose setae. Endopodite is a simple finger-shaped protuberance and as long as the basal joint of exopodite. Last pleopods (Fig. 3, I) are 2-segmented; the distal segment furnished with 6 plumose setae around the distal half of the segment and a simple hair on the outer edge. Telson is roughly quadrate.

\section{REFERENCES}

ArkawA, H. 1941. Additional notes to brachyuran larvae. Records of Oceanographic Works in Japan, Vol. 12, No. 2, pp. 117-120.

ARAgA, Ch., 1963. Round-year keeping of giant spider crab. Journal of Japanese Association of Zoological Gardens and Aquariums, Vol. 5, No. 2, pp. 63-66. (In Japanese).

SAKAI, T. 1965. Brachyura in "New Illustrated Encyclopedia of the Fauna of Japan." Part II. Hokuryu-kan, Tokyo. [Macrocheira kaemferi: p. 673, fig. 1183.] (In Japanese). 